\title{
Application of Fuzzy Measure and Fuzzy Integral in Students Failure Decision Making
}

\author{
A.M.Mane ${ }^{1}$, T.D.Dongale ${ }^{1}$, M.S.Bapat ${ }^{2}$ \\ ${ }^{I}$ School of Nanoscience and Technology, Shivaji University, Kolhapur (M.S) India \\ ${ }^{2}$ Department of Mathematics, Willingdon College, Sangli (M.S) India
}

\begin{abstract}
The present paper discusses an application of fuzzy measure and corresponding fuzzy integral for the evaluation of students failure reasons. From the result it is clearly seen that Choquet Integral has a good choice in Decision making.
\end{abstract}

Keywords: Fuzzy measure, $\lambda$-Fuzzy measure, Fuzzy Integral

\section{Introduction}

The fuzzy set theory or in general fuzzy logic was first of all introduced by Lotfi Zadeh in 1965 in his famous paper 'Fuzzy Sets' [1]. The classical set theory consists with condition of pointed or sharp boundaries. In Classical set theory crisp sets are defined on characteristic functions whose values are either zero or one, while in the Fuzzy set theory the requirement of sharp boundaries is get replaced by membership grades which are lies between 0 and 1 [2]. Fuzzy logic is a very broad concept which includes fuzzy set theory, fuzzy measure, fuzzy integral, fuzzy control theory, fuzzy decision theory etc. The applications of fuzzy logic found in many domains. The fuzzy logic is applicable to many areas where human decision making plays an important role [3-7]. Biswas apply the fuzzy logic for student evaluation [8]. He performed the evaluation based on grading method and traditional marking method and a better method of evaluation called FEM is suggested using fuzzy set theory [8]. The extended version of Biswas evaluation method is carried out by Chen and his colleagues [9]. Gokmen et al reported the evaluation of student performance in laboratory applications using fuzzy logic [10].

Academic achievements of the students is depends on various things like Intelligence Quotient (IQ) or Learning Ability, Attendance or Regularity, Subject Liking, Responsibility etc. In general students academic performance is carried out by Examinations or Tests and the result shows their progress. Fuzzy measures are appropriate tools to represent information or opinion states [11]. The present paper discusses the application of $\lambda$-Fuzzy measure and corresponding Choquet, Sugeno Integral for student evaluation for their failure reasons and focuses the importance of regularity criteria.

\section{Basic Definitions}

Measure: The measure is one of the important concepts in Mathematics, which is a generalization of length function defined on set of intervals.

For any set $X$, the collection $\beta$ of subsets of $X$ is called $\sigma$-algebra if,

(i) $\phi \in \beta, X \in \beta$

(ii) $B$ is closed under countable union

(iii) $B$ is closed under intersection

The pair $(X, B)$ is called measurable space. Thus measure is defined as follows,

2.1.1 Definition: Measure $\mu$ is a function defined on a measurable space $(X, \beta)$ is a non negative set function $\mu: \beta \rightarrow \mathrm{R}^{+}$defined for all sets $\beta$ and satisfying $\mu(\phi)=0$,

$\mu\left(\bigcup_{i=1}^{\infty} E_{i}\right)=\sum_{i=1}^{\infty} \mu\left(E_{i}\right)$ where $\left\{E_{i}\right\}$ is a sequence of disjoint measurable sets. i.e $E_{i} \cap E_{j}=\emptyset$ where $E_{i} \in \beta$ and $\beta$ is a $\sigma$-algebra. The $(X, \beta, \mu)$ is called measure space. There are various types of measures such as Counting measure, Lebesgue measure, Monotone measure, Probability measure etc. The Fuzzy measure is an extension of Probability measure.

\section{Monotone Measure:}

2.1.2 Definition: For any set $X$, Let $P(X)$ is the collection of all subsets of $X$. Then ${ }^{\top} P(X)$ is a $\sigma$-algebra and $(X, P(X))$ is a measurable space. A Set function $\mu:{ }^{\prime} P(X) \rightarrow[0, \infty]$ is called a monotone measure on $(X, P(X))$ if and only if it satisfies the following requirements, 
1. $\mu(\phi)=0$

2. If $\mathrm{E} \subseteq \mathrm{F}$ then $\mu(\mathrm{E}) \leq \mu(\mathrm{F})$ where $\mathrm{E}, \mathrm{F} \in \mathrm{P}(\mathrm{X})$
(Vanishing at the empty set)

(Monotonicity)

$(\mathrm{X}, \mathrm{P}(\mathrm{X}), \mu)$ is called monotone Measure Space.

Fuzzy Measure: In fuzzy measure, additivity of the measure is replaced with a weaker condition of monotonicity. The main characteristic of a (non-monotonic) fuzzy measure is the non-additivity, so that a (nonmonotonic) fuzzy measure is also known as non-additive measure [12].

2.2 Definition: Mathematically the fuzzy measure is defined as follows:

Let $X=\left\{x_{1}, x_{2}, x_{3} \ldots, x_{n}\right\}$ the set of criteria, and $P(X)$ the power set of $X$, i.e. the set of all subsets of $X$. A fuzzy measure on $\mathrm{X}$ is a continuous or semi continuous set function,

$\mu:{ }^{'} \mathrm{P}(\mathrm{X}) \rightarrow[0,1]$,satisfying the following axioms,

1. $\mu(\phi)=0$ and $\mu(X)=1$.

2. If $\mathrm{A}, \mathrm{B} \in \mathrm{P}(\mathrm{X})$, if $\mathrm{A} \subseteq \mathrm{B}$ then $\mu(\mathrm{A}) \leq \mu(\mathrm{B})$.

(Boundary conditions)

(Monotonicity)

This kind of measure is more flexible than a probability, which is constrained by its additivity property [13]. Fuzzy measures can give a larger or a smaller value (by sub additivity or super additivity condition)

$\lambda$ - Measure (Sugeno's $\lambda$ - Fuzzy Measure): The most common type of monotone measure in literature is the $\lambda$ measure (Sugeno's $\lambda$-fuzzy measure) [14].

2.3 Definition: Let $X$ be a finite set. $\lambda$ - Measure ( Sugeno's $\lambda$ - Fuzzy Measure) is a nonnegative set function $g_{2}:{ }^{\circ} \mathrm{P}(\mathrm{X}) \rightarrow[0,1]$ satisfying,

$g_{\lambda}(\mathrm{A} \cup \mathrm{B})=g_{\lambda}(\mathrm{A})+g_{\lambda}(\mathrm{B})+\lambda g_{\lambda}(\mathrm{A}) g_{\lambda}(\mathrm{B})$ for all $\mathrm{A}, \mathrm{B} \in \mathrm{X}$ whenever $\mathrm{A} \cap \mathrm{B}=\phi$ Where, $\lambda$ is a parameter $\lambda \in(-1, \infty)$.

Moreover $\mathrm{X}$ be a finite set $\mathrm{X}=\left\{\mathrm{x}_{1}, \mathrm{x}_{2}, \mathrm{x}_{3}, \ldots \mathrm{x}_{\mathrm{n}}\right\}$. The $g_{\lambda}(\mathrm{X})$ can be formulated as follows, [19]

$g_{\lambda}(X)=g_{\lambda}\left(\left\{x_{1}, x_{2}, x_{2} \ldots x_{n}\right\}\right)=\sum_{i=1}^{n} g_{\lambda}\left(\left\{x_{i}\right\}\right)+\lambda \sum_{i=1}^{n-1} \sum_{j=2}^{n} g_{\lambda}\left(\left\{x_{i}\right\}\right) g_{\lambda}\left(\left\{x_{j}\right\}\right)+\lambda^{2}$

$\sum_{i=1}^{n-2} \sum_{j=2}^{n-1} \sum_{k=3}^{n} g_{\lambda}\left(\left\{x_{i}\right\}\right) g_{\lambda}\left(\left\{x_{j}\right\}\right) g_{\lambda}\left(\left\{x_{k}\right\}\right)+\ldots .+\lambda^{n-1} g_{\lambda}\left(\left\{x_{1}\right\}\right) \cdot g_{\lambda}\left(\left\{x_{2}\right\}\right) \ldots g_{\lambda}\left(\left\{x_{n}\right\}\right)$

The Parameter $\lambda$ can be calculated as stated in the theorem below.

2.3.1Theorem [14]: Let $\mathrm{X}=\left\{\mathrm{x}_{1}, \mathrm{x}_{2}, \mathrm{x}_{3} \ldots \mathrm{x}_{\mathrm{n}}\right\}$ where $\mathrm{n} \geq 2$ and $g_{\lambda}$ be a $\lambda$ measure on $\mathrm{P}(\mathrm{X})$, $\mathrm{knowing}$ $g_{\lambda}\left(\left\{\mathrm{x}_{\mathrm{i}}\right\}\right)=\mathrm{a}_{\mathrm{i}} \geq 0$ (with atleast two of them being nonzero) and $g_{\lambda}(\mathrm{X})=\mathrm{b} \geq \mathrm{a}_{\mathrm{i}}, \mathrm{i}=1,2,3 \ldots \mathrm{n}$. The value of $\lambda$ can be uniquely determined by equation, $\mathrm{b} \lambda+1=\prod_{i=1}^{n}\left(1+\mathrm{a}_{\mathrm{i}} \lambda\right)[14]$.

It can be write as $\mathrm{b} \lambda+1=\prod_{i=1}^{n}\left(1+b \cdot g_{\lambda}\left(\left\{\mathrm{x}_{\mathrm{i}}\right\}\right) \cdot \lambda\right)$ Since $g_{\lambda}(\mathrm{X})=1=\mathrm{b}$,

Therefore above equation can be written as $\lambda+1=\prod_{i=1}^{n}\left(1+g_{\lambda}\left(\left\{\mathrm{x}_{\mathrm{i}}\right\}\right) . \lambda\right)$

When, $\lambda<0$ then $\lambda$-measure is sub additive measure.

$\lambda=0$ then $\lambda$-measure is an additive measure.

$\lambda>0$ then $\lambda$-measure is super additive measure.

\subsubsection{Construction of $\boldsymbol{\lambda}$-fuzzy measure:}

If values of basic elements are given then it is possible to obtain value of $\lambda$ for which $g_{\lambda}$ is a fuzzy measure.

Example: $X=\left\{\mathrm{x}_{1}, \mathrm{x}_{2}, \mathrm{x}_{3}\right\} g_{\lambda}\left(\left\{\mathrm{x}_{1}\right\}\right)=0.4, g_{\lambda}\left(\left\{\mathrm{x}_{2}\right\}\right)=0.3, g_{\lambda}\left(\left\{\mathrm{x}_{3}\right\}\right)=0.2$

The value of $\lambda$ can be calculated by using equation (2)

$\lambda+1=\prod_{i=1}^{n}\left(1+g_{\lambda}\left(\left\{\mathrm{x}_{\mathrm{i}}\right\}\right) \cdot \lambda\right)$

$\lambda+1=(1+0.4 \lambda) \cdot(1+0.3 \lambda) \cdot(1+0.2 \lambda)$

$0.024 \lambda^{3}+0.26 \lambda^{2}-0.1 \lambda=0$, The roots of this equation will be $\{0.3719,0,-11.87\}$. But we know that $\lambda$ is a parameter $\lambda \in(-1, \infty)$. 
For $\lambda=0, g_{\lambda}$ is an additive measure. Thus we consider only a single value $\lambda=0.3719$

$$
\begin{aligned}
& g_{\lambda}\left(\left\{\mathrm{x}_{1}\right\}\right)=0.4, \\
& g_{\lambda}\left(\left\{\mathrm{x}_{2}\right\}\right)=0.3, \\
& g_{\lambda}\left(\left\{\mathrm{x}_{3}\right\}\right)=0.2 \\
& g_{\lambda}\left(\left\{\mathrm{x}_{1}, \mathrm{x}_{2}\right\}\right)=g_{\lambda}\left(\left\{\mathrm{x}_{1}\right\}\right)+g_{\lambda}\left(\left\{\mathrm{x}_{2}\right\}\right)+\lambda g_{\lambda}\left(\left\{\mathrm{x}_{1}\right\}\right) \cdot g_{\lambda}\left(\left\{\mathrm{x}_{2}\right\}\right)=0.7446 \\
& g_{\lambda}\left(\left\{\mathrm{x}_{1}, \mathrm{x}_{3}\right\}\right)=g_{\lambda}\left(\left\{\mathrm{x}_{1}\right\}\right)+g_{\lambda}\left(\left\{\mathrm{x}_{3}\right\}\right)+\lambda g_{\lambda}\left(\left\{\mathrm{x}_{1}\right\}\right) \cdot g_{\lambda}\left(\left\{\mathrm{x}_{3}\right\}\right)=0.6298 \\
& g_{\lambda}\left(\left\{\mathrm{x}_{2}, \mathrm{x}_{3}\right\}\right)=g_{\lambda}\left(\left\{\mathrm{x}_{2}\right\}\right)+g_{\lambda}\left(\left\{\mathrm{x}_{3}\right\}\right)+\lambda g_{\lambda}\left(\left\{\mathrm{x}_{2}\right\}\right) \cdot g_{\lambda}\left(\left\{\mathrm{x}_{3}\right\}\right)=0.5223 \\
& g_{\lambda}(\mathrm{X})=1
\end{aligned}
$$

As $g_{\lambda}$ is satisfies all conditions of fuzzy measure. The $g_{\lambda}$ is a $\lambda$-fuzzy measure for $\lambda=0.3719$.

\subsection{Aggregation by fuzzy integral}

This paper introduces an outline of the aggregation problem and discusses the details of fuzzy integral. Aggregation operators are used to combine several numerical values into a single one. The properties of the aggregation operator can be divided into two families such as, mathematical properties and the behavioral properties $[15,16]$.

The mathematical properties show a correct aggregation of criteria while the behavioral properties express the relations between criteria, decisional performance etc. Common aggregation operators [17] present some drawbacks. Arithmetic mean, weighted mean, median, mode etc. none is capable to find interaction between criteria. The Choquet and Sugeno Integral with respect to monotone measures stand for a useful tool in multicritria decision making. The Fuzzy Integral is a special type of nonlinear integral with respect to fuzzy measure which was introduced in 1974. Integrals are used as an aggregation tools in Information fusion and Data mining, successfully. Here Choquet and Sugeno Integrals are defined. Choquet and Sugeno Integrals are used as an aggregation operator without these drawbacks. These two Integrals are only differ in the used operators sum and product for the Choquet integral, maximum and minimum for the Sugeno integral [18].

Choquet Integral: This is one of the types of nonlinear integral with respect to non additive measure. Choquet Integral is more suitable for measure with probability related interpretation.

2.5 Definition: Let $f$ be a non negative measurable function on $(\mathrm{X}, \beta)$ and $E \in \beta$. The Choquet Integral of $f$ : $\mathrm{X} \rightarrow[0, \infty]$ on $\mathrm{E}$ with respect to $\lambda$-Fuzzy measure $\mathrm{g}_{\lambda}$ (Monotone measure) denoted by, $(c) \int_{E} f d g_{\lambda}$ is given by (c) $\int_{E} f d g_{\lambda}=\sum\left[f\left(x_{i}^{*}\right)-f\left(x_{i-1}^{*}\right)\right] g_{\lambda}\left(\left\{x_{i}^{*}, x_{i+1}^{*} \ldots x_{n}^{*}\right\}\right)$

where, $f\left(x_{o}^{*}\right)=0,\left\{x_{n+1}^{*}, \ldots x_{n}^{*}\right\}=\phi$, and $\left(x_{1}^{*}, x_{2}^{*} \ldots x_{n}^{*}\right)$ is a permutation of $\mathrm{E}=\left\{x_{1_{0}} x_{2} \ldots x_{n}\right\}$ such that,

$f\left(x_{1}^{*}\right) \leq f\left(x_{2}^{*}\right) \leq f\left(x_{3}^{*}\right) \leq \cdots \leq f\left(x_{n}^{*}\right)$.

Sugeno Integral: Sugeno Integral is more proper for the fuzzy related interpretation.

2.6.Definition: $\int f d g_{\lambda}=\operatorname{Max}\left[\min \left(f\left(x_{1}^{*}\right), g_{\lambda}\left(\left\{x_{1}^{*}, x_{2}^{*}, x_{3}^{*} \ldots \ldots x_{n}^{*}\right\}\right)\right), \min \left(f\left(x_{2}^{*}\right)\right.\right.$,

$$
\left.\left.g_{\lambda}\left(\left\{x_{2}^{*}, x_{3}^{*} \ldots x_{n}^{*}\right\}\right)\right), \min \left(f\left(x_{3}^{*}\right), g_{\lambda}\left(\left\{x_{3}^{*}, x_{4}^{*} \ldots x_{n}^{*}\right\}\right)\right) \ldots \min \left(f\left(x_{n}^{*}\right), g_{\lambda}\left(\left\{x_{n}^{*}\right\}\right)\right)\right] .
$$

The fuzzy integral with respect to a fuzzy measure has mainly been studied in a multi-criteria decision making framework $[15,17]$

\section{Case Study}

The student failure is one of the key issue which faces by many academic institutes. There are many reasons by which students to be failed in Examination system. By continuous evaluation of students by using present case study one can predicts important criteria for success and possibility of success. By discussing with the number of students from some Institute and their teachers, it is found that the students fail in the Examination due to various reasons. Some major reasons for failure are tabulated in the table 1. 
Table 1: Failure Reasons and Criteria

\begin{tabular}{rll}
\hline Sr. No. & \multicolumn{1}{c}{ Failure Reasons } & \multicolumn{1}{c}{ Criteria } \\
\hline 1) & Lack of concentration & Intelligence Quotient $($ IQ) or Learning \\
Ability $\left(\mathrm{C}_{1}\right)$ & \\
2) & Poor Classroom Attendance or irregular due to Travelling or Financial problem.etc. & Attendance or Regularity $\left(\mathrm{C}_{2}\right)$ \\
3) & Lack of Motivation, Wrong teaching habits etc & Subject Liking $\left(\mathrm{C}_{3}\right)$ \\
4) & Careless behavior of students, Lack of Time- & Responsibility $\left(\mathrm{C}_{4}\right)$ \\
& Management and willingness. Lack of maturity, Peer Relationships etc. & \\
5) & Examination Phobia, Overconfidence, Wrong reading and Writing habits, Mental & Unavoidable conditions $\left(\mathrm{C}_{5}\right)$ \\
& Stress, Accident, illness, Sudden death of family member &
\end{tabular}

Table 2: Linguistic Scales for the Importance Weight

\begin{tabular}{ccc}
\hline & Extremely & 0.0 \\
If the criteria is less & Highly & 0.1 \\
& Very & 0.2 \\
& Strongly & 0.3 \\
\hline Medium & Quite & 0.4 \\
\hline & Medium & 0.5 \\
\hline If the criteria is more & Quite & 0.6 \\
& Strongly & 0.7 \\
& Very & 0.8 \\
\hline
\end{tabular}

Let $\{A, B, C, \ldots J\}$ be the set of 10 students observed for the five criteria $C_{1}, C_{2}, C_{3}, C_{4}, C_{5}$ their values according the above scale are given in the table 3 . Here grades are given to each student for different criteria by taking their IQ test (for $\mathrm{C}_{1}$ ), from Attendance report (for $\mathrm{C}_{2}$ ), by giving Questioner (for $\mathrm{C}_{3}$ ) and by discussing with students, their friends, parents and teachers (for $\mathrm{C}_{4}$ and $\mathrm{C}_{5}$ )

Table 3: Criteria Wise Students Grades

\begin{tabular}{cccccc}
\hline $\begin{array}{c}\text { Criteria } \\
\text { Students }\end{array}$ & C1 & C2 & C3 & C4 & C5 \\
\hline A & 0.9 & 0.2 & 0.7 & 0.2 & 0.8 \\
B & 0.1 & 0.9 & 0.8 & 0.2 & 0.8 \\
C & 0.1 & 0.2 & 0.9 & 0.8 & 0.2 \\
D & 0.2 & 0.1 & 0.6 & 0.8 & 0.2 \\
E & 0.4 & 0.8 & 0.1 & 0.5 & 0.3 \\
F & 0.6 & 0.7 & 0.8 & 0.5 & 0.3 \\
G & 0.6 & 0.2 & 0.3 & 0.4 & 0.5 \\
H & 0.7 & 0.5 & 0.8 & 0.8 & 0.1 \\
I & 0.4 & 0.2 & 0.1 & 0.5 & 0.3 \\
J & 0.4 & 0.2 & 0.1 & 0.3 & 0.9 \\
\hline
\end{tabular}

Example: For student D the value of the criteria $C_{1}$ is 0.2 means the student D has very less IQ or learning ability Where,

$\mathrm{C}_{1}$ : Intelligence Quotient (IQ) or Learning Ability

$\mathrm{C}_{2}$ : Attendance or Regularity

$\mathrm{C}_{3}$ : Subject Liking

$\mathrm{C}_{4}$ : Responsibility

$\mathrm{C}_{5}$ : Unavoidable condition

\subsection{Construction of $\lambda$-fuzzy measure:}

We construct $\lambda$-fuzzy measure as a set of Criteria.

Let $\mathrm{X}=\left\{\mathrm{C}_{1}, \mathrm{C}_{2}, \mathrm{C}_{3}, \mathrm{C}_{4}, \mathrm{C}_{5}\right\}$.

In this case study by Educationalist from Education department were selected as Expert. A short survey was done by asking them to rate the degree of importance (Here as a passing grades) for these five criteria Table 4 shows the Judgment of relative importance of passing grades by Experts. 
Table 4: Judgment of Relative Importance of Passing Grades by Experts

\begin{tabular}{ccccc}
\hline $\mathbf{C}_{1}$ & $\mathbf{C}_{2}$ & $\mathbf{C}_{3}$ & $\mathbf{C}_{4}$ & $\mathbf{C}_{5}$ \\
\hline 0.5 & 0.8 & 0.6 & 0.6 & 0.5 \\
\hline
\end{tabular}

We assume that $g_{\lambda}\left(\left\{\mathrm{C}_{1}\right\}\right)=0.5, g_{\lambda}\left(\left\{\mathrm{C}_{2}\right\}\right)=0.8, g_{\mathcal{\lambda}}\left(\left\{\mathrm{C}_{3}\right\}\right)=0.6, g_{\lambda}\left(\left\{\mathrm{C}_{4}\right\}\right)=0.6, g_{\mathcal{\lambda}}\left(\left\{\mathrm{C}_{5}\right\}\right)=0.5$ where $\lambda$ is to be determined. Here Sugeno's $\lambda$ - fuzzy measure is used to compute the Interdependency occurred between the selected criteria. From equation (1), the value of parameter $\lambda$ is calculated as, $\lambda+1=(1+0.5 \lambda) .(1+0.8 \lambda) .(1+0.6 \lambda) .(1+0.6 \lambda) \cdot(1+0.5 \lambda)$

By solving above fifth degree equation, we get 5 roots of the above equation. Among these two are complex conjugates. As $\lambda \in(-1, \infty)$ we reject two complex roots. Remaining three are $0,-0.991369,-3.8161$. Again-3.8161Æ $(-1, \infty)$.Thus accepted values of $\lambda$ are 0 and -0.9914 . The $\lambda$ value is negative, this implies the existence of negative multiplicative effect between the criteria However, if $\lambda=0$ then $g_{\lambda}$ becomes additive measure which shows that there is no relations between the attributes $C_{1}, C_{2}, C_{3}, C_{4}, C_{5}$ since which is not reality. Thus $\lambda=-0.991369 \approx-0.9914 \in(-1, \infty)$. As there are 5 criteria so it is necessary to define $2^{5}$ i.e. 32 subsets of criteria, from table 4 we have,

$$
g_{\lambda}\left(\left\{\mathrm{C}_{1}\right\}\right)=0.5, g_{\lambda}\left(\left\{\mathrm{C}_{2}\right\}\right)=0.8, g_{\lambda}\left(\left\{\mathrm{C}_{3}\right\}\right)=0.6, g_{\lambda}\left(\left\{\mathrm{C}_{4}\right\}\right)=0.6, g_{\lambda}\left(\left\{\mathrm{C}_{5}\right\}\right)=0.5
$$

From equation (1), for $\lambda=-0.9914$

$$
\begin{aligned}
g_{\lambda}\left(\left\{\mathrm{C}_{1}, \mathrm{C}_{2}\right\}\right) & =g_{\boldsymbol{\lambda}}\left(\left\{\mathrm{C}_{1}\right\}\right)+g_{\boldsymbol{\lambda}}\left(\left\{\mathrm{C}_{2}\right\}\right)+\lambda g_{\boldsymbol{\lambda}}\left(\left\{\mathrm{C}_{1}\right\}\right) \cdot g_{\boldsymbol{Z}}\left(\left\{\mathrm{C}_{2}\right\}\right) \\
& =0.5+0.8+(-0.9914)(0.5)(0.8) \\
& =0.9034
\end{aligned}
$$

Similarly by using equation (1), one can calculate the other values. The following Table 5 and 6 shows the calculated values, which indicates the interdependencies between two or more criteria.

Table 5: The Interdependencies measures among $C_{i}$ 's

\begin{tabular}{cccc}
$\begin{array}{c}\text { Between two } \\
\text { criteria }\end{array}$ & $\begin{array}{c}\text { Interdependencies measure } \\
\text { or } \lambda \text {-Measure }\end{array}$ & $\begin{array}{c}\text { Among three } \\
\text { criteria }\end{array}$ & $\begin{array}{c}\text { Interdependencies measure } \\
\text { or } \lambda \text {-Measure }\end{array}$ \\
\hline $\mathrm{C}_{1}, \mathrm{C}_{2}$ & 0.9034 & $\mathrm{C}_{1}, \mathrm{C}_{2}, \mathrm{C}_{3}$ & 0.9660 \\
$\mathrm{C}_{1}, \mathrm{C}_{3}$ & 0.8026 & $\mathrm{C}_{1}, \mathrm{C}_{2}, \mathrm{C}_{4}$ & 0.9660 \\
$\mathrm{C}_{1}, \mathrm{C}_{4}$ & 0.8026 & $\mathrm{C}_{1}, \mathrm{C}_{2}, \mathrm{C}_{5}$ & 0.9565 \\
$\mathrm{C}_{1}, \mathrm{C}_{5}$ & 0.7521 & $\mathrm{C}_{1}, \mathrm{C}_{3}, \mathrm{C}_{4}$ & 0.8852 \\
$\mathrm{C}_{2}, \mathrm{C}_{3}$ & 0.9241 & $\mathrm{C}_{1}, \mathrm{C}_{3}, \mathrm{C}_{5}$ & 0.9047 \\
$\mathrm{C}_{2}, \mathrm{C}_{4}$ & 0.9241 & $\mathrm{C}_{1}, \mathrm{C}_{4}, \mathrm{C}_{5}$ & 0.9047 \\
$\mathrm{C}_{2}, \mathrm{C}_{5}$ & 0.9034 & $\mathrm{C}_{2}, \mathrm{C}_{3}, \mathrm{C}_{4}$ & 0.9745 \\
$\mathrm{C}_{3}, \mathrm{C}_{4}$ & 0.8431 & $\mathrm{C}_{2}, \mathrm{C}_{3}, \mathrm{C}_{5}$ & 0.9660 \\
$\mathrm{C}_{3}, \mathrm{C}_{5}$ & 0.8026 & $\mathrm{C}_{2}, \mathrm{C}_{4}, \mathrm{C}_{5}$ & 0.9660 \\
$\mathrm{C}_{4}, \mathrm{C}_{5}$ & 0.8026 & $\mathrm{C}_{3}, \mathrm{C}_{4}, \mathrm{C}_{5}$ & 0.8852 \\
\hline
\end{tabular}

Table 6: The Interdependencies Measures Among Four Criteria's

\begin{tabular}{cc}
\hline Among four criteria & $\begin{array}{c}\text { Interdependencies measure } \\
\text { or } \lambda \text {-Measure }\end{array}$ \\
\hline $\mathrm{C}_{1}, \mathrm{C}_{2}, \mathrm{C}_{3}, \mathrm{C}_{4}$ & 0.9915 \\
$\mathrm{C}_{1}, \mathrm{C}_{2}, \mathrm{C}_{3}, \mathrm{C}_{5}$ & 0.9872 \\
$\mathrm{C}_{1}, \mathrm{C}_{2}, \mathrm{C}_{4}, \mathrm{C}_{5}$ & 0.9872 \\
$\mathrm{C}_{1}, \mathrm{C}_{3}, \mathrm{C}_{4}, \mathrm{C}_{5}$ & 0.9660 \\
$\mathrm{C}_{2}, \mathrm{C}_{3}, \mathrm{C}_{4}, \mathrm{C}_{5}$ & 0.9915 \\
\hline
\end{tabular}

Based on above table, the pair of $\mathrm{C}_{2}, \mathrm{C}_{3}$ and $\mathrm{C}_{3}, \mathrm{C}_{4}$ received the highest interdependency measure whereas the pair $\mathrm{C}_{1}, \mathrm{C}_{5}$ has the least degree of relations. Also this table shows that estimated measures of interdependencies among three and four criteria. It is observed that $\mathrm{C}_{2}, \mathrm{C}_{3}, \mathrm{C}_{4}$ received the highest 
interdependency measure. Table 6 shows highest interdependence between $C_{1}, C_{2}, C_{3}, C_{4}$ and $C_{2}, C_{3}, C_{4}, C_{5}$. It is observed that absence of $\mathrm{C}_{2}$ gives lowest value. Since these criteria are not independent their simple arithmetic mean will not represent the proper index. We combine these five criteria using Choquet and Sugeno Integration with respect to $\lambda$-fuzzy measure $\left(g_{\lambda}\right)$

\subsection{Calculation of Choquet and Sugeno Integral}

The aggregate values of criteria by using Choquet and Sugeno Integral for student ' $\mathrm{A}$ ' is as follows and for other students the aggregate values are depicted in table 7.

i. Aggregation by Choquet Integral by using definition 2.5,

$f\left(\mathrm{c}_{1}^{*}\right)=C_{2}=0.2, f\left(c_{2}^{*}\right)=C_{4}=0.2, f\left(C_{3}^{*}\right)=C_{3}=0.7$

$f\left(c_{4}^{*}\right)=C_{5}=0.8, f\left(c_{5}^{*}\right)=C_{1}=0.9$.

(c) $J_{E} f d g_{\lambda}=\sum\left[f\left(c_{i}^{*}\right)-f\left(c_{i-1}^{*}\right)\right] g_{\lambda}\left(\left\{c_{i}^{*}, c_{i+1}^{*} \ldots c_{n}^{*}\right\}\right)$ where, i $=1,2,3,4$, and 5 .

$$
=0.7776
$$

ii. Aggregation by Sugeno Integral by using definition 2.6,

$$
\begin{aligned}
\int f d g_{\lambda}= & \operatorname{Max}\left[\min \left(f\left(c_{1}^{*}\right), g_{\lambda}\left(\left\{c_{1}^{*}, c_{2}^{*}, c_{3}^{*}, c_{4}^{*}, c_{5}^{*}\right\}\right)\right), \min \left(f\left(c_{2}^{*}\right), g_{\lambda}\left(\left\{c_{2}^{*}, c_{3}^{*}, c_{4}^{*}, c_{5}^{*}\right\}\right)\right),\right. \\
& \left.\min \left(f\left(c_{3}^{*}\right), g_{\lambda}\left(\left\{c_{3}^{*}, c_{4}^{*}, c_{5}^{*}\right\}\right)\right), \min \left(f\left(c_{4}^{*}\right), g_{\lambda}\left(\left\{c_{4}^{*}, c_{5}^{*}\right\}\right)\right), \min \left(f\left(c_{5}^{*}\right), g_{\lambda}\left(\left\{c_{5}^{*}\right\}\right)\right)\right] . \\
& =0.7521
\end{aligned}
$$

Table 7: Calculated Values of Choquet and Sugeno Integral as an Aggregation Tool.

\begin{tabular}{ccc}
\hline Students & Passing index by Choquet Integral & Passing index by Sugeno Integral \\
\hline A & $0.7776 \approx_{0.78}$ & $0.7521 \approx_{0.75}$ \\
B & $0.8588 \approx_{0.86}$ & 0.8 \\
C & $0.7408 \approx_{0.74}$ & 0.8 \\
D & $0.653 \approx_{0.65}$ & 0.6 \\
E & $0.7264 \approx 0.73$ & 0.8 \\
F & $0.7473 \approx 0.75$ & 0.7 \\
G & $0.5124 \approx_{0.51}$ & 0.5 \\
H & $0.7579 \approx_{0.76}$ & 0.8 \\
I & $0.4295 \approx_{0.43}$ & 0.5 \\
J & $0.6144 \approx_{0.61}$ & 0.5 \\
\hline
\end{tabular}

It is observed that passing index calculated by Choquet integral gives more better values than the Sugeno integral for comparison. This due to fact that the aggregate values by Sugeno integral are get affected by max-min operators. The table 4 shows the judgment of relative importance of passing grades by experts and it is 0.5 and above. Here the passing index given by Choquet integral for student B is 0.86 , which shows that the student B will definitely pass in the examination. While in case of student I, it is 0.43 which shows that student I will definitely fail.

\section{Conclusion}

This paper presents the measures of relative importance and interdependencies among the five main criteria for student's failure prediction. The case study results show that the, regularity is one of the important criteria for passing in the examination among all criteria and it also affects the passing grade index. More Index value indicates possibility of more success. The results clearly indicate that Choquet integral is better than Sugeno integral as an aggregation tool for this case study. 


\section{References}

[1] L. A. Zadeh, Fuzzy sets, Information and control, 8(3), 1965, 338-353.

[2] D. J. Dubois, Fuzzy sets and systems: theory and applications (Vol. 144), (Academic Press, 1980).

[3] T. D. Dongale, T .G. Kulkarni, S. V. Kulkarni, S. R. Jadhav, R. R. Mudholkar, AC Induction Motor Control-Neuro-Fuzzy approach, International Journal of Engineering Science \& Advanced Technology, 2(4), 2012, 863 - 870

[4] T. D. Dongale, T .G. Kulkarni, R. R. Mudholkar, Fuzzy Modelling of Voltage Standing Wave Ratio using Fuzzy Regression Method, International Journal of Emerging Technology and Advanced Engineering, 2(6), 2012, 2250-2459.

[5] T. D. Dongale, S. R. Ghatage, R. R. Mudholkar, Application Philosophy of Fuzzy Regression, International Journal of Soft Computing and Engineering,2(6), 2013, 170-173

[6] T. D. Dongale, T .G. Kulkarni, S. R. Ghatage, R. R. Mudholkar, Implementation and Comparative study of Three Phase Induction Motor Control Using PID Controller, Fuzzy Logic and Neural Network Techniques, International Journal of Advanced and Innovative Research, 1(6), 2012, 271-275.

[7] S. R. Ghatage, T. D. Dongale, T .G. Kulkarni, R. R. Mudholkar, Development of Fuzzy Inference Scheme for LC Oscillator Design, International Journal of Engineering Research and Development, 3(12), 2012, 91-98

[8] R. Biswas, An application of fuzzy sets in students' evaluation, Fuzzy sets and systems, 74(2), 1995, 187-194.

[9] S. M. Chen, \& C. H. Lee, New methods for students' evaluation using fuzzy sets, Fuzzy sets and systems, 104(2), 1999, 209-218.

[10] G. Gokmen, T. Ç. Akinci, M. Tektaş, N. Onat, G. Kocyigit, \& N. Tektaş, Evaluation of student performance in laboratory applications using fuzzy logic, Procedia-Social and Behavioral Sciences, 2(2), 2010, 902-909.

[11] L. Campos. M. Lamata and S. Moral, Distances between fuzzy measures through associated probabilities: some applications, Fuzzy Sets and Systems, 35, 1990, 57-68.

[12] M. Grabisch, T. Murofushi, M. Sugeno, Fuzzy measure and Integral, Theory and applications, (Springer-Verlag 1999)

[13] H. Zulzalil, A. Ghani, M. Selamat, R. Mahmod, Using Fuzzy Integral to Evaluate the Web-based Applications, Malaysian Software Engineering Interest Group (MSEIG). Malaysia, 2011.

[14] Z. Wang, R. Yang, K. Leung, Nonlinear Integrals and their Applications in Data Mining, Advances in fuzzy systems-Applications and Theory, vol-24, (World Scientific publishing 2010).

[15] J. R. Fodor, Fuzzy Preference Modeling and Multicriteria Decision Support, (Dordrecht: Kluwer Academic Publisher, 1994).

[16] M. Grabisch, H. T. Nguyen, and E. A. Walker, Fundamental of Uncertainty Calculi with Applications to Fuzzy Inference (Dordrecht: Kluwer Academics Publishers, 1995)

[17] M. Detyniecki, Fundamentals of Aggregation Operators, LIP6 Research Report:2001-2002, University of California, Berkeley, 2001.

[18] L. G. Campos, Bolafios, Characterization and comparison of Sugeno and Choquet integrals, Fuzzy Sets and Systems, 52, 1992, 61-67.

[19] K. Leszczyński, P. Penczek, and W. Grochulski, Sugeno’s fuzzy measure and fuzzy clustering, Fuzzy Sets and Systems, 15, 1985, $147-158$ 